\title{
Hind Limb Sensory Innervation in Rats: Comparison between Sural and Saphenous Nerve Morphometry
}

\author{
Inervación Sensorial de los Miembros Posteriores en Ratas: \\ Comparación Morfométrica entre los Nervios Sural y Safeno
}

\author{
Letícia Oliveira Neri*; Milena Menezes de Amorim*; Stella Andrade Rodrigues Campos*; \\ Luciana Sayuri Sanada* \& Valéria Paula Sassoli Fazan*****
}

\begin{abstract}
NERI, L. O.; DE AMORIM, M. M.; CAMPOS, S. A. R.; SANADA, L. S. \& FAZAN, V. P. S. Hind limb sensory innervation in rats: Comparison between sural and saphenous nerve morphometry. Int. J. Morphol., 33(2):743-750, 2015.

SUMMARY: Although numerous studies investigate sensory recovery of the hind paw of the rat after nerve damage, still no comprehensive overview of its normal innervation is present in the literature. We investigated the morphometry of myelinated fibers in the sural and saphenous nerves and analyzed their size distributions in young rats. Six 30-day-old female Wistar rats were perfused with $2.5 \%$ glutaraldehyde and their right and left sural and saphenous nerves were prepared for light microscopy and morphometry. Morphometric data were compared between segments (proximal versus distal) and sides (right versus left) for the same nerves. Also, segments from right or left sides were compared between nerves (sural versus saphenous). Both, the sural and saphenous nerves, exhibited proximal to distal symmetry on both sides as well as left-right symmetry. Histograms of the diameter of the myelinated fibers were unimodal in both nerves, regardless of segments or sides with the peaks of the fibers size occurring between 2.5 and $4.0 \mu \mathrm{m}$. The axon distributions reflected the myelinated fiber distributions, with the sural and saphenous nerves peaking between 1.5 and $2.0 \mu \mathrm{m}$. The $\mathrm{G}$ ratio (the ratio between the axon and fiber diameters) distributions were also unimodal, with peaks at 0.6 for both nerves. This study contributes to the literature with information on the myelinated fibers morphometry from the two sensory nerves responsible for the rat hind limb innervation. This information is valuable for a better understanding of the possible contribution of collateral sprouting from the sural or saphenous nerves on the paw sensory territory recovery observed after one of these nerves is damaged.
\end{abstract}

KEY WORDS: Sural nerve; Saphenous nerve; Morphometry; Myelinated fibers.

\section{INTRODUCTION}

Sural nerves from rats are often described as one of the three direct sciatic nerve branches (Schmalbruch, 1986) and its sensory function is commonly investigated after the sciatic nerve injury. The major source of sensory fibers for the sural nerve in rats comes from spinal roots L4/L5 (Swett et al., 1991). In the more distal areas of the foot, the sural nerve is responsible for the sensory innervation of the lateral side and dorsal central area (Cobianchi et al., 2014) but it also contains a small percentage $(4 \%)$ of motor fibers (Swett et al.). The extensive use of the sural nerve in experimental investigations about degeneration and regeneration following nerve injury is described mainly from male rats (Unger et al., 1998) while the sural nerves from female rats was less investigated (Jeronimo et al., 2005, 2008).
The rat saphenous nerve originates as a femoral nerve terminal branch and receives contributions from the spinal roots L3/L4. At the ankle it gives terminal branches to the medial skin of the hind foot, including the heel and the tarsus (Kinnman et al., 1992). Different from the sural nerve, only somato-sensory fibers are present in the rat saphenous nerve and because of its superficial anatomical path in the hind limb, it has been used in experimental models involving neuropathic pain and its treatments (Gunduz et al., 2011). However, descriptive studies of the normal morphology and morphometry of the saphenous nerve in rats are still scanty, particularly for female rats (Campos et al., 2008).

Although numerous studies investigate sensory

\footnotetext{
* Department of Neuroscience and Behavioral Sciences, School of Medicine of Ribeirão Preto, University of São Paulo, Ribeirão Preto, Brazil.

** Department of Surgery and Anatomy, School of Medicine of Ribeirão Preto, University of São Paulo, Ribeirão Preto, Brazil.

Grant sponsor: FAPESP (Fundação de Amparo à Pesquisa do Estado de São Paulo); Grant numbers: 2013/01111-0, 2013/20549-7; Grant sponsor:

CNPq (Conselho Nacional de Pesquisa e Tecnologia); Grant number: 300900/2013-9. Grants assigned to VPS Fazan.
} 
recovery of the hind paw of the rat after nerve damage, still no comprehensive overview of its normal innervation is present in the literature (Kambiz et al., 2014). It has been demonstrated that after a saphenous nerve injury, the sural nerve is able to send collateral axon sprouting to the denervated saphenous area and this sprouting is $30 \%$ larger in females (Kovacic et al., 2003). Also, small myelinated axons from the saphenous nerve are able to sprout into the denervated skin after long term sciatic nerve injury (Kinnman et al.). Precise knowledge of the anatomic course and the common motor and sensory distributions of peripheral nerves can greatly assist in the interpretation of experimental results after nerve damage and reinnervation. Thus, we aimed to describe the normal morphology and morphometry of the sural and saphenous nerves in young female rats, investigating their longitudinal and lateral symmetry and also the similarities between nerves in terms of numeric data.

\section{MATERIAL AND METHOD}

Experiments were performed in female Wistar $(n=$ 6 ), born and raised in the animal care facility of the Department of Neurosciences and Behavioral Sciences, School of Medicine of Ribeirão Preto, in a controlled environment (room temperature between $21-23{ }^{\circ} \mathrm{C}$, air humidity between 40 and $70 \%$ and dark/light cycle of $12 \mathrm{~h}$ ). The animals were housed in plastic cages (3-4 animals to a cage) with free access to tap water and rat chow throughout the experiments. All experimental procedures adhered to The Guide for the Care and Use of Laboratory Animals prepared by the National Academy of Sciences and published by the National Institutes of Health (Copyright $(1996$ by the National Academy of Sciences), and were approved by the Institutional Ethics Committee for Animal Research (CETEA - Comitê de Ética em Experimentação Animal, protocol number 184/2005). Effort was made to minimize the number of animals used.

Animals with 30 days of age (mean body weight of $95 \pm 6 \mathrm{~g})$ were anesthetized with sodium thiopental (Thionembutal, $40 \mathrm{mg} \mathrm{kg}$, i.p.) and perfused through the left ventricle with a $0.05 \mathrm{M}$ phosphate-buffered saline solution, $\mathrm{pH} 7.4$, followed by a $2.5 \%$ glutaraldehyde solution in $0.1 \mathrm{M}$ cacodylate buffer, $\mathrm{pH}$ 7.2. Nerves were dissected without stretching from their origin through their distal branching. Sural nerves were dissected from their origin from the sciatic nerves to the lateral malleolus while saphenous nerves were dissected from the groin region to the medial malleolus. Right and left sural and saphenous nerves were removed in one piece and placed in the fixative solution for an additional 12 hours. They were washed in cacodylate buffer, $\mathrm{pH} 7.2$, and proximal (close to the origin) and distal (close to terminal branching) segments (of approximately 3 $\mathrm{mm}$ each) were cut and processed for epoxy resin embedding (EMbed-812®, Electron Microscopy Sciences, Hatfield, PA, USA) as described elsewhere (Jeronimo et al., 2005).

Semithin (0.2-0.3 mm thick) transverse sections of the fascicles were stained with $1 \%$ toluidine blue and examined with the aid of an Axiophot II photomicroscope (Carl Zeiss, Jena, Germany). The images were sent via a digital camera (TK- 1270, JVC, Victor Company of Japan Ltd., Tokyo, Japan) to an IBM/PC where they were digitized. For the study of myelinated fibers, the endoneural space was observed with an optical set including an oil immersion lens $(100 \mathrm{x})$, optovar $(1.6 \mathrm{x})$, camera $(0.5 \mathrm{x})$ and an $8 \mathrm{x}$ computerized magnification, which provided images with good resolution for morphometry.

The endoneural space was fully scanned without overlap of the microscopic fields, using an automatic motorized stage (Carl Zeiss, Jena, Germany). Scanning of sural nerves generated 9 to 33 microscopic fields, while saphenous nerves generated 8 to 12 microscopic fields. These microscopic fields of $640 ¥ 470$ pixels were used to count and automatically measure the myelinated fibers and their respective axons. Fibers at the upper and left edges of the microscopic fields were counted whereas those at the lower and right edges were not counted ("forbidden line") in order to avoid counting the same fiber twice. All myelinated fibers present in the endoneural space were counted. Morphometric parameters of the fascicles and myelinated fibers of sural and saphenous nerves segments were obtained as described previously (Campos et al.; Jeronimo et al., 2008). The total number of myelinated fibers and the total number of Schwann cell nuclei present in each transverse section of the fascicles were counted. The area and lesser diameter of each fascicle (excluding the perineurium) as well as each myelinated fiber (defined by the axon and its respective myelin sheath, excluding the Schwann cell nucleus when present) and respective axon (fiber excluding the myelin sheath) were measured with image analysis software (KS 400, Kontron 2.0, Eching Bei München, Germany). The lesser diameter was chosen because it is the best representation of the diameter of a non-circular fascicle and/ or fiber (Jeronimo et al., 2005). The area values were calculated directly by the software ("filled area" function) and not mathematically calculated from perimeter value. The myelinated fibers and Schwann cell nuclei densities were then calculated. The percentage of the total cross-sectional area of the endoneural space occupied by the myelinated fibers was calculated, and hereafter referred as the percentage of occupancy (Jeronimo et al., 2005, 2008; Campos et al.). For myelinated fibers, both axonal diameter and total fiber 
diameter were automatically measured. The ratio between the two diameters, the $\mathrm{g}$ ratio (which indicates the degree of myelination), was obtained (Rushton, 1951) and the myelin sheath area was measured for each myelinated fiber. For diameter measuring, fiber and axon forms are taken into account by calculating the "circularity index" for each fiber. When fibers present index higher than 0.45 , they are measured. Thus, fibers that are too oblong or irregular are automatically discharged. Histograms of diameter distribution of myelinated fibers and axons, separated into class intervals increasing by $0.5 \mathrm{~mm}$ were constructed. Histograms of the g ratio distribution separated into class intervals increasing by 0.1 were also studied. The investigators were blind to nerves identities throughout the morphometric procedures.

Morphometric data were tested for normal distribution by the Kolmogorov-Smirnov normality test followed by the Levene test for variance equivalence. If data presented a normal distribution and equivalent variance, comparisons were made between proximal and distal segments in the same nerves by paired Student's t-test. For comparisons between right and left segments in the same nerve or between sural and saphenous nerves the unpaired Student's ttest was used. When the data did not pass the normality test comparisons between proximal and distal segments were made by Wilcoxon's non-parametric test and Mann-Whitney test was used on the comparisons between right and left segments of the same nerve or between sural and saphenous nerves. Histograms were compared by analysis of variance (ANOVA) on Ranks provided that the distributions did not pass the normality test. Differences were considered significant when $\mathrm{p}<0.05$. Data are presented as mean \pm standard error of the mean (SEM).

\section{RESULTS}

Morphological aspects. Both, sural and saphenous nerves, showed good preservation of structures to allow the morphometric analysis by light microscopy (Fig. 1). Most proximal segments of sural nerves and all saphenous nerves proximal segment were monofasciculated. The distal segments of both nerves always presented two or more fascicles. The fascicles were well-defined, surrounded by a perineurium with a lamellar arrangement constituted of about 7-8 concentric layers (Fig. 1). In the endoneural space (Fig. 1), both nerves presented myelinated and unmyelinated fibers, capillary vessels with endothelial cells and pericytes, nuclei of Schawnn cells and fibroblasts, and mast cells. No differences on the endoneural structures were noticed between segments or sides of the sural and the saphenous nerves or between nerves.

Fascicle morphometry. Fascicle morphometry data (fascicular area and diameter, myelinated fiber number and density, Schwann cell nuclei number and density and percentage of occupancy of the myelinated fibers) is shown in Table I. The comparison between segments (proximal versus distal), either on the right or left sides, did not show differences on the fascicular parameters for both nerves. Likewise, the comparisons between right and left sides did not show differences for the sural or for the saphenous nerves.

The comparison between sural and saphenous nerves showed significant differences on fascicle area and diameter, the sural nerves being larger than the

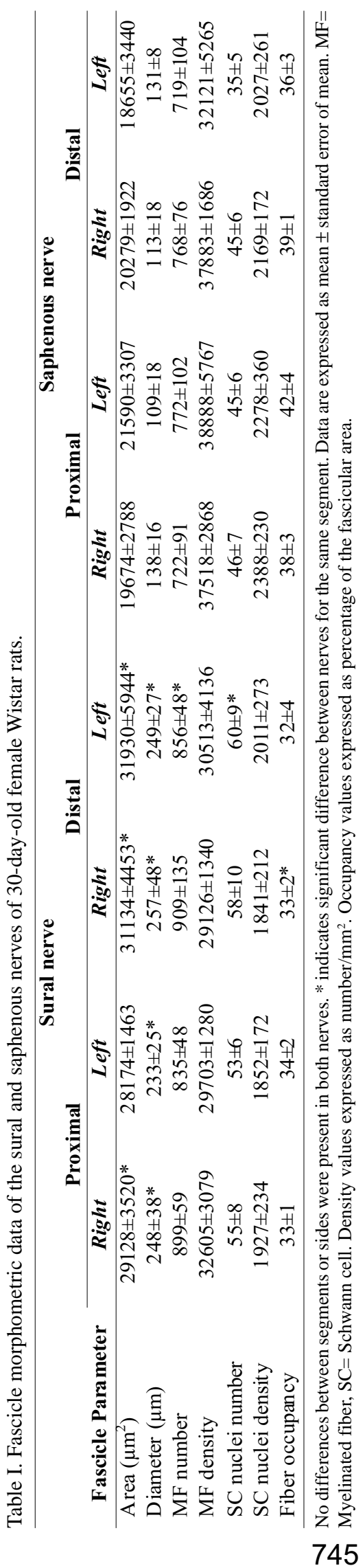




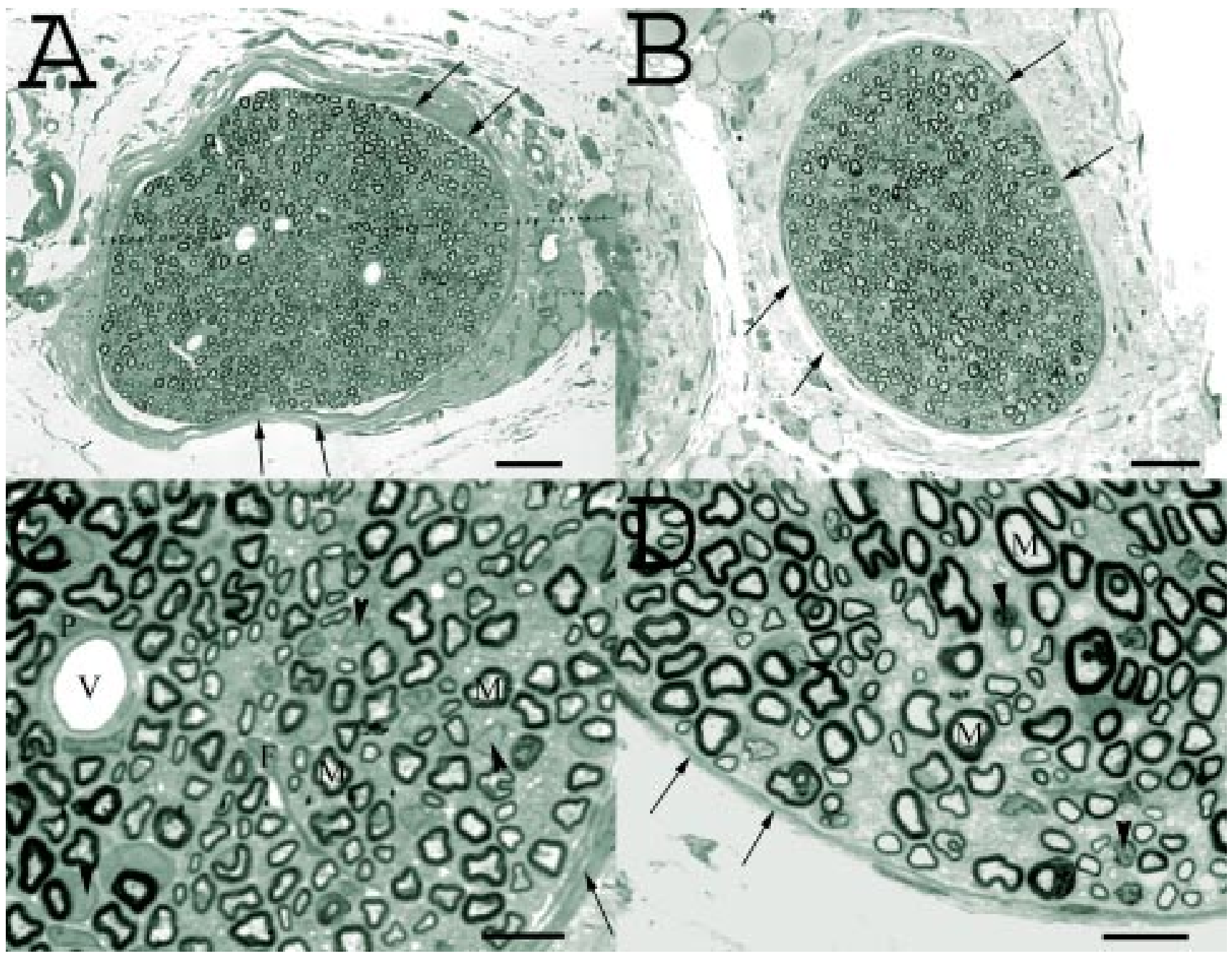

Fig. 1. Semithin sections of the sural (A) and saphenous (B) nerves from 30 days old female Wistar rats. The nerve fascicles are enveloped by the perineurium (arrows). Images $\mathrm{C}$ and $\mathrm{D}$ represent a higher magnification of the fascicles shown in $\mathrm{A}$ and $\mathrm{B}$ respectively. A large amount of myelinated fibers $(\mathrm{M})$ is present in the endoneural space, together with capillary blood vessels (V) with their associated pericyte $(\mathrm{P})$. F indicates a fibroblast nucleus. Arrowheads point to the Schwann cell nuclei. Toluidine blue stained; scale bar in A and B= $20 \mu \mathrm{m}$ and in $\mathrm{C}$ and $\mathrm{D}=10 \mu \mathrm{m}$.

saphenous nerves on each segment of both sides, except for the area on the left distal segment. Also, myelinated fiber number and Schwann cell nuclei number were larger on the distal left segment of the sural nerve, compared to the saphenous nerve. The myelinated fibers percentage of occupancy was significantly smaller only on the distal right segment of the sural nerve, compared to the saphenous (Table I).

Myelinated fibers morphometry. Myelinated fiber morphometry data (myelinated fiber and axon area, myelinated fiber and axon diameter, myelin sheath area and $\mathrm{G}$ ratio) is shown on Table II. The comparison between segments (proximal versus distal), on the right and left sides, did not show differences on the myelinated fiber parameters for both nerves. Likewise, there was no difference between sides either for the sural or for the saphenous nerves.

Size distribution histograms. Myelinated fibers diameters, myelinated axon diameter as well as the $\mathrm{G}$ ratio distributions are shown in Figure 2. Myelinated fiber diameter ranged between 1.0-7.5 $\mu \mathrm{m}$, with a plateau between $2.5-4.0 \mu \mathrm{m}$. The distribution of the myelinated axons diameter were skewed to the left in comparison with the distributions of fiber diameter, ranging from $0.5-4.5 \mu \mathrm{m}$, with a plateau between $1.5-2.0 \mu \mathrm{m}$. G ratio distribution ranged between $0.3-0.8$ with peaks at 0.6 . All histograms presented unimodal shape and there was no difference in the comparisons between segments and sides on the same nerve or between sural and saphenous nerves. 

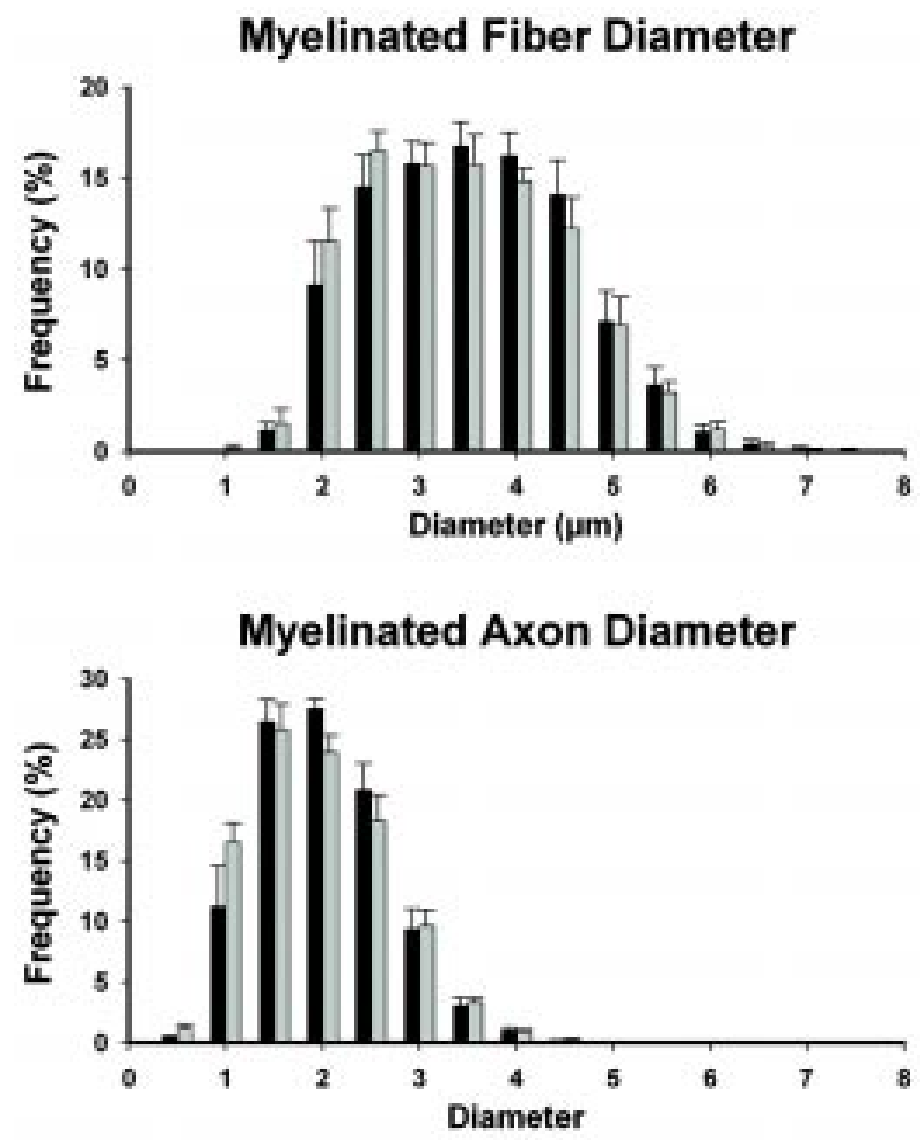

Myelinated Fiber $\mathbf{G}$ ratio

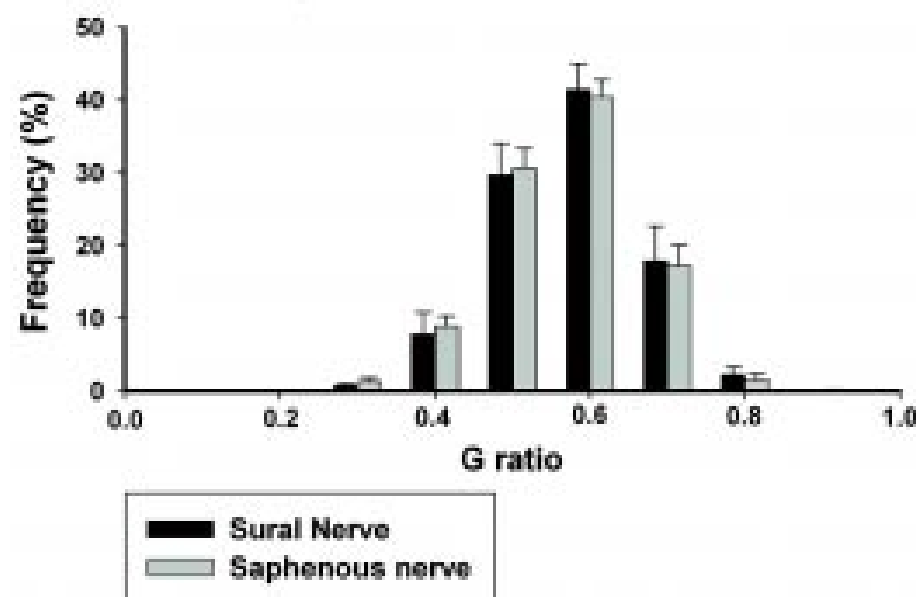

Fig. 2. Histograms representing the distribution of myelinated fibers, myelinated axons and $\mathrm{G}$ ratio of sural (solid black) and saphenous (grey) nerves from young ( 30 days of age) female Wistar rats. Only the proximal right segments are represented since no statistical difference was found between segments and sides on the same nerve. All represented distributions are unimodal, being the axon distributions skewed to the left compared to the fiber distributions. G ratio distributions showed the expected peaks at 0.6. No differences were observed between nerves.

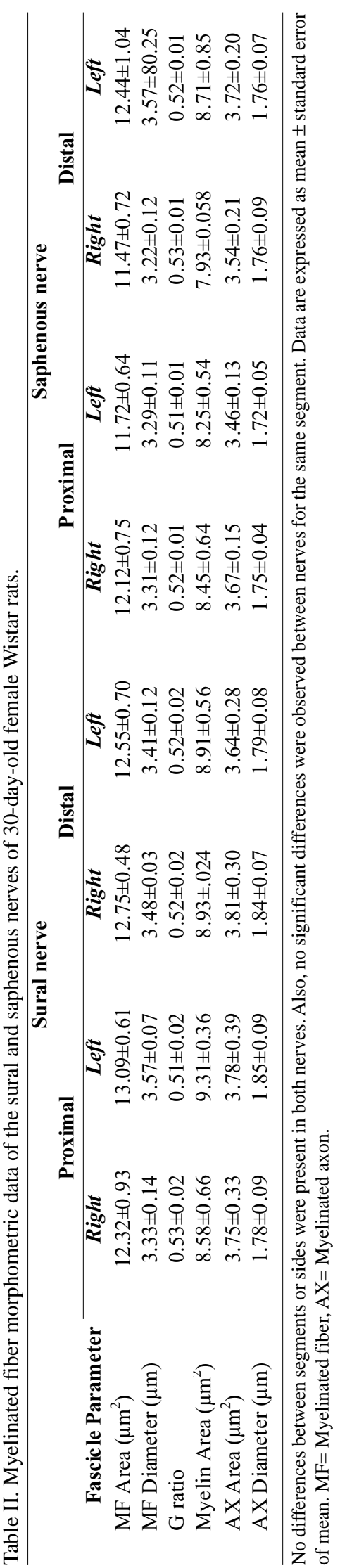




\section{DISCUSSION}

This study contributes to the literature with information on the myelinated fibers morphometry from the two sensory nerves responsible for the rat hind limb innervation, particularly the paws. The morphometric comparison between sural and saphenous nerves form the same animals are shown for the first time.

Our results showed that the sural and saphenous nerves are morphometrically symmetric from proximal to distal segments (longitudinal symmetry). This information is important since degenerative changes in peripheral nerves occur firstly in the distal portion of the fibers (Grover-Johnson \& Spencer, 1981). This is strongly indicative of that longitudinal studies in experimental neuropathies are mandatory. Also, we demonstrated a lateral symmetry on both nerves studied. Because lateral asymmetry is described in the literature in some peripheral nerves (Fraher, 1992; Rodrigues Filho \& Fazan, 2006), our investigation indicates that experimental studies involving injury of the sural or saphenous nerves might use the opposite side nerve as the control.

The present data on fascicle size, and myelinated fibers number and density from both nerves are similar with other studies that used animals with distinct ages or other rat strains (Campos et al.; Jeronimo et al., 2005, 2008; Knox et al., 1989; Saitua \& Alvarez, 1988). For the Schwann cells, it is well known that they participate in the regeneration processes after a nerve injury. Thus, knowledge the expected number of Schwann cell nuclei in a determined nerve is useful for regeneration investigations. The nerve regeneration process alters the endoneural content, particularly increasing the Schwann cell nuclei number, since the Schwann cell duplication rate is higher than the fibroblasts duplication rate (Thomas, 1948).

Donaldson \& Hoke (1905) were one of the first to describe the relation between the myelin sheath and the diameter of its axon. This relation may be different between nerves and also differ significantly between fiber classes (small or large fibers) in a determined nerve (Fraher). The $\mathrm{G}$ ratio values closer to 0.6 was defined by Rushton as the optimal ratio for the maximum conduction velocity of a myelinated fiber. The unimodal $\mathrm{G}$ ratio distribution, with peak at 0.6 observed in both sural and saphenous nerves indicates that animals with 30 days of life present myelinated fibers fully developed and prepared to the best spread of the current between two Ranvier nodes.

We used semi-automated morphometry to perform a quantitative description of the sural and saphenous nerves from young rats (fascicles as well as myelinated fibers). In spite of the great utilization of morphometric techniques in neuropathy studies, this technique has proven extremely useful for the definition of normal parameters of nerves, either in humans (O'Sullivan \& Swallow, 1968; Ochoa, 1971; Jacobs \& Love, 1985) or in laboratory animals (Friede \& Samorajski, 1967; Sato et al., 2006; Schiavoni \& Fazan, 2006). Thus, data obtained with morphometry is used as the morphological basis for investigation of systemic and/or local diseases that compromise the peripheral nervous system.

Studies involving sensory denervation of the hind paws usually access the sensory recovery through behavioral tests such as the von Frey monofilaments. Nevertheless, these behavioral tests often disregard the pattern of hind paw innervation (Cobianchi et al.). This may lead to confounding attribution of recovery of sensory responses to improvement in sural nerve (a sensory branch of the sciatic nerve) regeneration instead of collateral reinnervation by the undamaged saphenous nerve (a sensory branch form the femoral nerve) (Cobianchi et al.). In this case, the morphometric evaluation of the regenerated sural nerve, associated to the undamaged saphenous nerve would contribute to the interpretation of the sensory tests results.

In conclusion, this study adds useful morphometric information to understanding the patterns of innervation of intact and damaged sensory nerve fibers to the rat hind paws. This information is useful to a better understanding of the possible contribution of collateral sprouting from the sural or saphenous nerves on the paw sensory territory recovery observed after one of these nerves is damaged.

\section{ACKNOWLEDGMENTS}

We thank Mr. Antônio Renato Meirelles e Silva, Experimental Neurology Laboratory and Ms. Maria Tereza P. Maglia, Electron Microscopy Laboratory, School of Medicine of Ribeirão Preto, for excellent technical support.

NERI, L. O.; DE AMORIM, M. M.; CAMPOS, S. A. R.; SANADA, L. S. \& FAZAN, V. P. S. Inervación sensorial de los miembros posteriores en ratas: Comparación morfométrica entre los nervios sural y safeno. Int. J. Morphol., 33(2):743-750, 2015.

RESUMEN: Aunque numerosos estudios investigan la recuperación sensorial del miembro pélvico o posterior de la rata después del daño en los nervios, aún no existe en 
la literatura una visión global de su inervación normal. Investigamos la morfometría de fibras mielínicas de los nervios sural y safeno y analizamos sus distribuciones de tamaño en ratas jóvenes. Seis ratas Wistar de 30 días de edad fueron perfundidas con 2,5\% de glutaraldehído, se prepararon los nervios sural y safeno derecho e izquierdo para microscopía de luz y morfometría. Datos morfométricos fueron comparados entre los segmentos (proximal vs distal) y laterales (derecho vs izquierdo) para los mismos nervios. Además, los segmentos de los lados derecho e izquierdo se compararon entre los nervios (sural vs safeno). Ambos nervios sural y safeno exhibieron una simetría proximal a distal en ambos lados, así como una simetría izquierda-derecha. Histogramas del diámetro de las fibras mielinizadas eran unimodales en ambos nervios, independientemente de los segmentos o de los lados, siendo los peaks del tamaño de las fibras entre 2,5 y 4,0 micras. Las distribuciones de los axones reflejan las distribuciones de fibras mielinizadas, de los nervios sural y safeno que alcanzaban entre 1,5 and 2,0 $\mu \mathrm{m}$. La relación de $\mathrm{G}$ (relación entre los diámetros de los axones y de fibra) eran también unimodales, alcanzando 0,6 para ambos nervios. Este estudio contribuye a la literatura con los datos de la morfometría de fibras mielinizadas de ambos nervios sensoriales responsables de la inervación de la extremidad pélvica de la rata. Esta información es valiosa para una mejor comprensión de los nervios sural y safeno en la recuperación sensorial del miembro después de que uno de estos nervios ha sido dañado.

PALABRAS CLAVE: Nervio sural; Nervio safeno; Morfometría; Fibras mielinizadas.

\section{REFERENCES}

Campos, S. A.; Sanada, L. S.; Sato, K. L. \& Fazan, V. P. Morphometry of saphenous nerve in young rats. J. Neurosci. Methods, 168(1):8-14, 2008.

Cobianchi, S.; de Cruz, J. \& Navarro, X. Assessment of sensory thresholds and nociceptive fiber growth after sciatic nerve injury reveals the differential contribution of collateral reinnervation and nerve regeneration to neuropathic pain. Exp. Neurol., 255:1-11, 2014.

Donaldson, H. H. \& Hoke, G. W. On the areas of the axis cylinder and medullary sheath as seen in cross sections of the spinal nerves of vertebrates. J. Comp. Neurol. Psychol., 15(1):1-16, 1905.

Fraher, J. P. Myelin-axon relationships in the rat phrenic nerve: longitudinal variation and lateral asymmetry. J. Comp. Neurol., 323(4):551-7, 1992.
Friede, R. L. \& Samorajski, T. Relation between the number of myelin lamellae and axon circumference in fibers of vagus and sciatic nerves of mice. J. Comp. Neurol., 130(3):223-31, 1967.

Grover-Johnson, N. \& Spencer, P. S. Peripheral nerve abnormalities in aging rats. J. Neuropathol. Exp. Neurol., 40(2):155-65, 1981.

Gunduz, O.; Oltulu, C.; Guven, R.; Buldum, D. \& Ulugol, A. Pharmacological and behavioral characterization of the saphenous chronic constriction injury model of neuropathic pain in rats. Neurol. Sci., 32(6):1135-42, 2011.

Jacobs, J, M. \& Love, S. Qualitative and quantitative morphology of human sural nerve at different ages. Brain, 108(Pt. 4):897924, 1985.

Jeronimo, A.; Jeronimo, C. A.; Rodrigues-Filho, O. A.; Sanada, L. S. \& Fazan, V. P. A morphometric study on the longitudinal and lateral symmetry of the sural nerve in mature and aging female rats. Brain Res., 1222:51-60, 2008.

Jeronimo, A.; Jeronimo, C. A.; Rodrigues-Filho, O. A.; Sanada, L. S. \& Fazan, V. P. Microscopic anatomy of the sural nerve in the postnatal developing rat: a longitudinal and lateral symmetry study. J. Anat., 206(1):93-9, 2005.

Kambiz, S.; Baas, M.; Duraku, L. S.; Kerver, A. L.; Koning, A. H.; Walbeehm, E. T. \& Ruigrok, T. J. Innervation mapping of the hind paw of the rat using Evans Blue extravasation, Optical Surface Mapping and CASAM. J. Neurosci. Methods, 229:1527, 2014.

Kinnman, E.; Aldskogius, H.; Johansson, O. \& Wiesenfeld-Hallin, Z. Collateral reinnervation and expansive regenerative reinnervation by sensory axons into "foreign" denervated skin: an immunohistochemical study in the rat. Exp. Brain Res., 91(1):61-72, 1992.

Knox, C. A.; Kokmen, E. \& Dyck, P. J. Morphometric alteration of rat myelinated fibers with aging. J. Neuropathol. Exp. Neurol., 48(2):119-39, 1989.

Kovacic, U.; Sketelj, J. \& Bajrovic, F. F. Sex-related difference in collateral sprouting of nociceptive axons after peripheral nerve injury in the rat. Exp. Neurol., 184(1):479-88, 2003.

O'Sullivan, D. J. \& Swallow, M. The fibre size and content of the radial and sural nerves. J. Neurol. Neurosurg. Psychiatry, 31(5):464-70, 1968.

Ochoa, J. The sural nerve of the human foetus: electron microscope observations and counts of axons. J. Anat., 108(Pt. 2):231-45, 1971.

Rodrigues Filho, O. A. \& Fazan, V. P. Streptozotocin induced diabetes as a model of phrenic nerve neuropathy in rats. $J$. Neurosci. Methods, 151(2):131-8, 2006. 
NERI, L. O.; DE AMORIM, M. M.; CAMPOS, S. A. R.; SANADA, L. S. \& FAZAN, V. P. S. Hind limb sensory innervation in rats: Comparison between sural and saphenous nerve morphometry. Int. J. Morphol., 33(2):743-750, 2015.

Rushton, W. A. A theory of the effects of fibre size in medullated nerve. J. Physiol., 115(1):101-22, 1951.

Saitua, F. \& Alvarez, J. Do axons grow during adulthood? A study of caliber and microtubules of sural nerve axons in young, mature, and aging rats. J. Comp. Neurol., 269(2):203-9, 1988.

Sato, K. L.; do Carmo, J. M. \& Fazan, V. P. Ultrastructural anatomy of the renal nerves in rats. Brain Res., 1119(1):94-100, 2006.

Schiavoni, M. C. \& Fazan, V. P. There is no relation between the fascicular and the endoneural blood vessel areas on the cervical vagus nerve of normotensive rats. J. Neurosci. Methods, 158(2):171-8, 2006.

Schmalbruch, H. Fiber composition of the rat sciatic nerve. Anat. Rec., 215(1):71-81, 1986.

Swett, J. E.; Torigoe, Y.; Elie, V. R.; Bourassa, C. M. \& Miller, P. G. Sensory neurons of the rat sciatic nerve. Exp. Neurol., 114(1):82-103, 1991.

Thomas, G. A. Quantitative histology of Wallerian degeneration: II. Nuclear population in two nerves of different fibre spectrum. J. Anat., 82(Pt. 3):135-45, 1948.

Unger, J. W.; Klitzsch, T.; Pera, S. \& Reiter, R. Nerve growth factor (NGF) and diabetic neuropathy in the rat: morphological investigations of the sural nerve, dorsal root ganglion, and spinal cord. Exp. Neurol., 153(1):23-34, 1998.
Correspondence to:

Valéria Paula Sassoli Fazan, M.D., Ph.D.

Department of Surgery and Anatomy

School of Medicine of Ribeirão Preto, USP.

Av. Bandeirantes 3900

Ribeirão Preto, SP

14049-900

BRAZIL

\section{Email:vpsfazan@yahoo.com.br vpsfazan@gmail.com}

Received: 11-11-2014

Accepted: 09-03-2015 